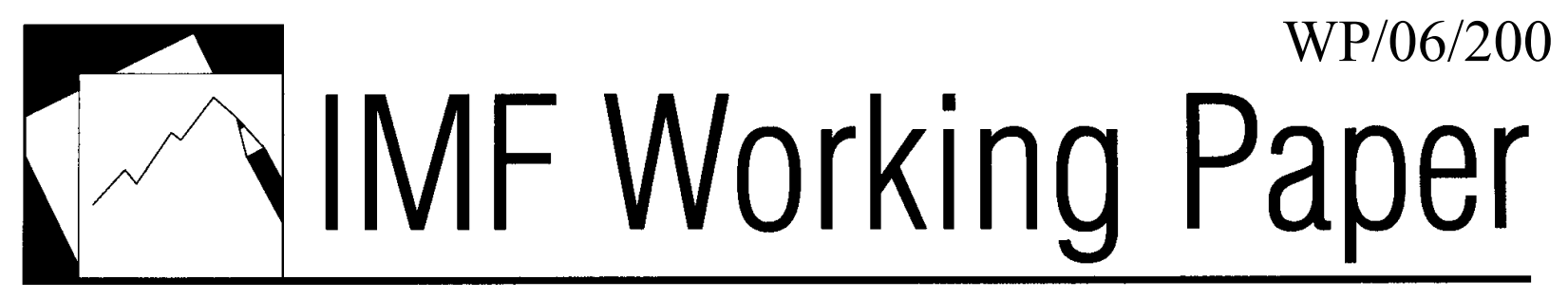

\title{
Asset-Market Participation, Monetary Policy Rules, and the Great Inflation
} Florin Bilbiie and Roland Straub 


\title{
IMF Working Paper
}

Asia and Pacific Department

\section{Asset-Market Participation, Monetary Policy Rules, and the Great Inflation}

\author{
Prepared by Florin Bilbiie and Roland Straub ${ }^{1}$
}

Authorized for distribution by Nissanke Weerasinghe

September 2006

\begin{abstract}

\section{This Working Paper should not be reported as representing the views of the IMF.} The views expressed in this Working Paper are those of the author(s) and do not necessarily represent those of the IMF or IMF policy. Working Papers describe research in progress by the author(s) and are published to elicit comments and to further debate.
\end{abstract}

This paper argues that limited asset market participation is crucial in explaining U.S. macroeconomic performance and monetary policy before the 1980s, and their changes thereafter. We develop an otherwise standard sticky-price dynamic stochastic general equilibrium model, which implies that at low asset-market participation rates, the interest rate elasticity of output (the slope of the IS curve) becomes positive-that is, "non-Keynesian." Remarkably, in that case, a passive monetary policy rule ensures equilibrium determinacy and maximizes welfare. Consequently, we argue that the policy of the Federal Reserve System in the pre-Volcker era, often associated with a passive monetary policy rule, was closer to optimal than conventional wisdom suggests and may thus have remained unchanged at a fundamental level thereafter. We provide institutional and empirical evidence for our hypothesis, in the latter case using Bayesian estimation techniques, and show that our model is able to explain most features of the "Great Inflation."

JEL Classification Numbers: E31, E32, E44, E52, E58, E65, N12, N22

Keywords: Great Inflation, Limited Asset Market Participation, Passive Monetary Policy

Author(s) E-Mail Address: florin.bilbiie@nuffield.ox.ac.uk; rstraub@imf.org

\footnotetext{
${ }^{1}$ Florin Bilbiie is Research Fellow at the University of Oxford, Nuffield College, and Roland Straub is an Economist at the International Monetary Fund. We thank Roberto Perotti, Giancarlo Corsetti, Jordi Galí, Andrew Scott, Mike Woodford, Roger Farmer, Kosuke Aoki, Mike Artis, Gianluca Benigno, Paul Bergin, Giuseppe Bertola, Fabrice Collard, Marco DelNegro, Mike Haliassos, Stephanie Schmitt-Grohe, Fabio Ghironi, Nobu Kiyotaki, David Lopez-Salido, Albert Marcet, Alex Michaelides, Tommaso Monacelli, John Muellbauer, Gernot Mueller, Kris Nimark, Fabrizio Perri, Paolo Pesenti, Pau Rabanal, Thomas Sargent, Frank Schorfheide, Jon Skinner, and Jaume Ventura for comments. Participants at the CEPR's 2004 European Summer Symposium in Macroeconomics in Tarragona, and seminars at London School of Economics, CREI-Universitat Pompeu Fabra, Nuffield College, Oxford, European University Institute, Birkbeck, IGIERBocconi, IMF; and DOFIN provided valuable comments. All remaining errors are ours.
} 


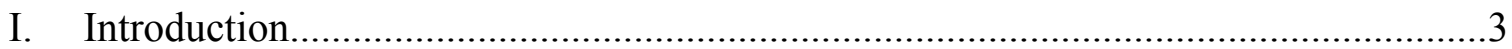

II. Limited Asset Market Participation and Monetary Policy: Some Theory.....................5

A. "Inverted Taylor Principle" and Optimal Passive Monetary Policy ...................... 9

III. Empirical Evidence.......................................................................................... 13

A. Institutional Evidence for Change in Asset-Market Participation ........................14

B. Bayesian Estimation of Structural Model ...........................................................16

IV. Change in Structure of Economy or in Distribution of Shocks? .............................22

A. Asset-Market Participation, Monetary Policy, and the Propagation of Shocks.....23

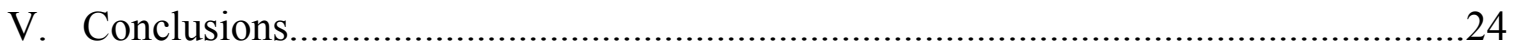

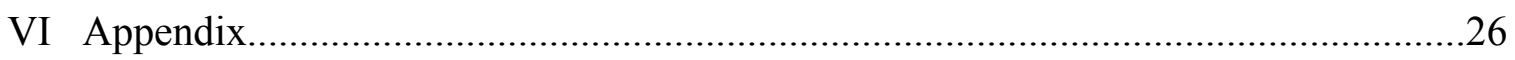

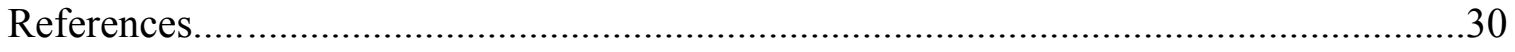

Tables

1. Prior Distribution for DSGE Model Parameters .................................................. 18

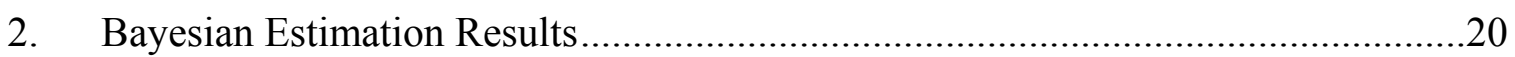

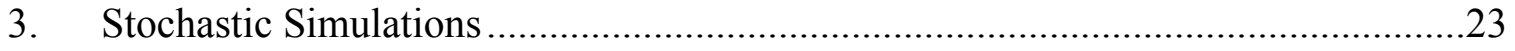

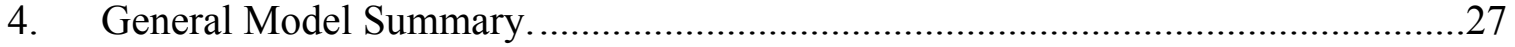

Figures

1. Keynesian and Non-Keynesian Crosses .........................................................

2. Impulse Reponse Functions Following a Cost-Push Shock ................................28

3. Impulse Reponse Functions Following an Aggregate Demand Shock...................29 


\section{INTRODUCTION}

"The seventies were indeed special." - Alan Blinder (1982)

It is widely documented that during the late 1960s and throughout the 1970s, inflation was high, volatile, and persistent, and a few recessions hit the U.S. economy. ${ }^{2}$ This historical record, which is known as the "Great Inflation" episode, was followed by a period, beginning in the early 1980 s, where the level, variance, and the persistence of the inflation rate, and the volatility of output decreased significantly. The latter phenomenon was labeled in the literature as the period of the "Great Moderation." Some of the theories put forward to explain this historical record rely on "mistakes" of the Federal Reserve System (Fed) during the "Great Inflation" period. ${ }^{3}$ Most of these theories, however, have difficulties explaining why this record has changed since the early 1980s. At a deeper level, theories relying upon a change in the Fed's behavior to explain the change in macroeconomic performance fail to explain why Fed behavior itself has changed.

In this paper, we outline a framework that can help explain the Great Inflation without relying on policy mistakes while, at the same time explaining why both macroeconomic performance and the Fed's behavior have changed. The central ingredient in our analysis is the dramatic change in financial markets that took place around 1980, leading to more widespread participation in asset markets. We put together institutional evidence from a variety of sources showing that financial constraints were especially binding in the 1970s and that deregulation and financial innovation led to more widespread participation since the early 1980s. In contrast, we present a standard business-cycle model with limited asset-market participation that predicts that if asset-market participation is low, aggregate demand, contrary to conventional wisdom, is positively related to real interest rates. We show that in our theoretical model, this finding implies that Fed policy in the pre-1980 years was consistent with both equilibrium determinacy and welfare maximization. Furthermore, we argue that the change in the policy rule from passive pre-1980 to active post-1980 could have been an endogenous response to the change in market participation, required by optimal policy.

We use Bayesian estimation techniques to estimate our model on U.S. data on two samples,

\footnotetext{
${ }^{2}$ See for example, DeLong (1997) for a historical account of the "Great Inflation" and also Columns 1 and 3 of Table 3 for the stylized facts.

${ }^{3}$ Some theories rely on "bad luck," taken to come from either: (i) larger shocks that generated greater overall variability and a more difficult policy environment (e.g. Blinder (1982), and Sargent (2002)); or (ii) an "honest mistake": the Fed was overestimating the natural rate throughout the 1970s (Orphanides, 2002; Collard and Dellas, 2004). This theory does not explain, howver, why the good performance occured in the 1950s and first half of 1960s, nor why policy response changed in 1980. Others blame policymakers directly: DeLong (1997) and Romer and Romer (2002) argue that the Fed was too averse towards recessions because of the Great Depression leaving its mark - if this is so, it is hard to explain why the United States did not have high inflation earlier. Chari, Christiano, and Eichenbaum (1999) emphasize "expectations traps": inflationary policy, they argue, was pursued because it is a self-fulfilling equilibrium feature of discretionary policy.
} 
corresponding to the pre- (Paul) Volcker and the Volcker-(Alan) Greenspan periods. Our results indicate that there have been major changes in the U.S. economy between the two subsamples, pertaining to both the structure of the economy (deep parameters) and the stochastic environment (shock processes). Most notably, (i) the share of agents participating in asset markets has changed from a lower to a higher value, generating a change in the sign of the IS-curve slope from positive (contrary to standard theory) to negative (as predicted by standard theory); and (ii) the response of monetary policy changed from "passive" to "active." Owing to these changes, the equilibrium was determinate throughout the whole period; moreover, monetary policy conduct was consistent with minimizing overall macroeconomic variability, as required by welfare maximization.

To our knowledge, the findings that the IS curve's slope changed sign and, moreover, that this change came from a change in asset market participation are entirely novel and have striking implications for interpreting the Great Inflation and reassessing the Fed's policy. ${ }^{4}$ Since our results show that shock processes have also changed, we run counterfactual experiments to study the relative importance of the "structure" versus "shocks" explanations of the changes in outcomes between the two subsamples. We find that although most of the changes can be accounted for by changes in the structure, changes in shock processes are also needed to explain some key facts (namely, the fall in the volatility of output). Finally, we show that the dynamic effects and propagation of fundamental shocks, in particular of "cost-push" and "aggregate demand" shocks, generated by our model are in line with stylized facts, and the bulk of the change in this transmission across the two samples is accounted for by the changes in asset-market participation and monetary policy conduct.

Our approach is most closely related to the large literature investigating the link between monetary policy and macroeconomic performance, with a particular focus on the Great Inflation and U.S. monetary policy in the 1970s. Some recent prominent contributions in this vein include Clarida, Galí, and Gertler (referred to as CGG) (2000), Taylor (1999), Lubik and Schorfheide (referred to as LS) (2004) and Ireland (2004). These studies estimate policy rules relating the policy instrument (a short term nominal interest rate) to macroeconomic variables such as expected inflation and output gap. All the cited papers identified a change in monetary policymaking with the coming to office of Paul Volcker as chairman of the Fed. Specifically, monetary policy was accommodative ("passive") in the pre-Volcker years, increasing nominal interest rates less than one-to-one when expected inflation increased. In contrast, Fed policy was more restrictive ("active") during the Volcker and Greenspan tenures. Since macroeconomic performance also changed, explaining the observed structural break by the change in the conduct of monetary policy became the norm in the profession.

The previously-mentioned studies argue that policy before Volcker was "badly" conducted along one or several dimensions, which led to worse macroeconomic performance as compared with the Volcker-Greenspan era. To make this point, estimated policy rules are embedded into

\footnotetext{
${ }^{4}$ Bilbiie and Straub (2006) run single-equation, reduced-form Generalized Method of Moments (GMM) estimations of an Euler equation for output and find that the coefficient on the interest rate has changed sign in the early 1980s.
} 
calibrated general equilibrium models to study the dynamics and variability of macroeconomic variables. These theoretical predictions are then compared with stylized facts. CGG (2000) were the first to argue that the passive policy rule in the pre-Volcker sample led to equilibrium indeterminacy and left room for sunspot fluctuations, which instead led to a higher level and variability of inflation, and overall macroeconomic instability. This approach has four obvious difficulties, however, in explaining the Great Inflation: (i) sunspot shocks increase both inflation and output (and the output gap), something not seen in the data; (ii) in the theoretical model, the effects of fundamental shocks cannot be studied when equilibrium is indeterminate; (iii) the dynamics of the whole economy are entirely dependent upon the stochastic properties, the location, and the origin of the sunspot shock, all of which impossible to quantify in practice; and (iv) it is not clear why the Fed would have followed a policy that was so clearly suboptimal, given the model? ${ }^{5}$

The plan of our paper is as follows. In Section II, we outline the theoretical framework consisting of a standard "new-synthesis" model augmented for limited asset market participation and derive analytically its main theoretical implications. Section III provides empirical evidence of our hypothesis. First, we present institutional evidence on the change in U. S. asset market participation in the early 1980s. Then, we estimate a dynamic stochastic general equilibrium (DSGE) model with limited-asset market participation using Bayesian methods. In Section IV, we show that the estimated model is able to reproduce some of the stylized facts of the U.S. economy, most notably the changes in macroeconomic outcomes; we assess quantitatively the relative merits of explanations of these changes based on changes of the structure, on the one hand, and of the stochastic environment, on the other hand. Section V contains concluding remarks.

\section{Limited Asset Market Participation and Monetary Policy: Some Theory.}

In this section, we briefly outline a theory that allows the analysis of monetary policy under limited asset market participation while treating the degree of asset market participation as a parameter that can be exogenously influenced by policy. The framework is a modification of the by now standard dynamic sticky price cashless general equilibrium model, similar to the workhorse model in for example, Woodford (2003) or CGG (1999). The modification is that we allow for limited asset market participation, or "segmented asset markets": part of the agents (asset holders) trade in complete asset markets including a market for shares in firms, while the other agents (non-asset holders) do not trade any assets and hence receive only a wage income. The share of non-asset holders, say $\lambda$, is exogenous, as in for example, Alvarez, Lucas, and Weber (2001). ${ }^{6}$ These agents will fail to smooth consumption as in Mankiw (2000) or Galí, López-Salido,

\footnotetext{
${ }^{5}$ Christiano and Gust (1999) address point (i) and show that in a limited participation model a sunspot shock to inflationary expectations can decrease output. But the other problems still remain.

${ }^{6}$ Our model shares with Alvarez, Lucas, and Weber (2001) only the structure of asset markets. Their paper focuses on a completely different question, in particular on the presence of a liquidity effect under market segmentation. In their framework, all agents hold currency, whereas our model is cashless. Finally, our model incorporates a Philips curve relationship.
} 
and Valles (referred to as GLV) (2003b), where this comes from the failure to accumulate physical capital.

The model outlined here is related to the framework in GLV (2003b) and Bilbiie (2003). In contrast to GLV (2003b), however, we derive a model that abstracts from capital accumulation and focuses on a different set of questions namely, how the presence of non-asset holders alters the slope of the aggregate Euler equation (IS curve), determinacy properties of interest rate rules, optimal monetary policy, and the response of the model economy to various fundamental shocks. ${ }^{7}$ In contrast to Bilbiie (2003), we use these theoretical insights to re-interpret the Great Inflation episode by estimating the model on U.S. data using Bayesian techniques and running counterfactual experiments. The chosen framework is well suited for our exercise for at least four reasons. First, it emphasizes the effect of non-asset holders on aggregate demand, which we wish to test empirically. Second, it derives analytically the "Inverted Taylor Principle" as a generically necessary condition for both equilibrium uniqueness and optimal policy when enough agents do not participate to asset markets. Third, it is directly comparable with and nests as a special case models such as CGG (2000) and LS (2004), which interpret the Great Inflation episode using estimated policy rules and comparing them to prescriptions dictated by theoretical models. Fourth, the absence of capital accumulation allows us to obtain analytical results and be transparent about the mechanism at work. Notably, optimal policy can be analyzed in a tractable way.

The exposition here is stripped down to the essential, ${ }^{8}$ although the main results carry through to more general specifications of preferences and technology (see Bilbiie (2003) for details). A more general model that is estimated in the next section is described in detail in the Appendix.

Suppose aggregate expenditure consists of consumption only. There are two types of households: asset holders indexed by $S$, trading state-contingent assets and shares in firms and non-asset holders indexed by $H$, who do not participate in any of the asset markets and simply consume their current income. ${ }^{9}$ The shares of these agents are $1-\lambda$ and $\lambda$, respectively, and are assumed to be constant. Total consumption in log-linear deviations from steady state is given

${ }^{7} \mathrm{GLV}(2003 b)$ are the first to study determinacy properties of interest rate rules when some agents do not hold capital, but their analysis relies on numerical simulations and is further complicated by the presence of capital and non-separable utility, which change determinacy properties dramatically.

${ }^{8}$ Notably, we abstract from fundamental shocks (such as technology) that move the "natural" levels of output and interest rates, although we do introduce these shocks when estimating the model, allowing for an arbitrary stochastic structure.

${ }^{9}$ In the background of nonparticipation in asset markets, there could be many reasons (constraints or preferences); but as long as all reasons have the same observational consequence, their relative importance is immaterial for our purposes. Our preffered explanation consists of constraints such as transactions costs; recent theoretical and empirical research shows that such market frictions alone could account for the observed participation shares (see for example Vissing-Jorgensen (2002)). 
by $c_{t}=\lambda c_{H, t}+[1-\lambda] c_{S, t}$, where $c_{j, t}$ is consumption of group $j .{ }^{10}$ Suppose furthermore for simplicity that labor supply of non-asset holders is inelastic $n_{H, t}=0$, such that their consumption is equal to the real wage $c_{H, t}=w_{t}$ and total labor supply is given by $n_{t}=[1-\lambda] n_{S, t}$. Assume that asset holders" labor supply obeys a standard optimality condition $\varphi n_{S, t}=w_{t}-c_{S, t}$, where $\varphi$ is the inverse Frisch elasticity of labor supply for type $S$. Total consumption will hence be: $c_{t}=\lambda w_{t}+[1-\lambda] c_{S, t}=\lambda \varphi_{S} n_{S, t}+c_{S, t}=\frac{\lambda}{1-\lambda} \varphi n_{t}+c_{S, t}$. Finally, assume that the production function for final output in log-linear form is $y_{t}=[1+\mu] n_{t}$, where $\mu$ represents both the steady-state net mark-up and the degree of aggregate increasing returns to scale. Using this we obtain a version of the "planned expenditure" or "aggregate demand" equation from standard Keynesian models: ${ }^{11}$

$$
c_{t}=c\left(\begin{array}{c}
y_{t}, r r_{t} \\
+-
\end{array}\right)=\frac{\lambda}{1-\lambda} \frac{\varphi}{1+\mu} y_{t}+c_{S, t} .
$$

This equation links aggregate expenditure to current income and consumption of asset holders. Note that (1) is not a reduced-form relationship since $c_{t}, y_{t}, c_{S, t}$ are all endogenous variables, which will be determined in general equilibrium. However, we can think of (1) as a schedule in the $(y, c)$ space, for a given level of $c_{S, t}$. In that sense, we can say that aggregate demand (expenditure) depends positively on current income and negatively on the real interest rate. We can define the (partial) "marginal propensity to consume" out of current income as $\partial c / \partial y=\frac{\lambda}{1-\lambda} \frac{\varphi}{1+\mu}>0$. This "marginal propensity to consume" is in fact a partial marginal propensity, that is keeping fixed consumption of asset holders $c_{S}$. In equilibrium, of course, all output is consumed. We will loosely refer to $\partial c / \partial y$ as "marginal propensity to consume" in the remainder. The negative impact of ex-ante real interest rates $r r_{t} \equiv r_{t}-E_{t} \pi_{t+1}$ on aggregate demand comes from a standard Euler equation for consumption of asset-holders: $c_{S, t}=E_{t} c_{S, t+1}-\left[r_{t}-E_{t} \pi_{t+1}\right]$, where $r$ is the nominal interest rate and the intertemporal elasticity of substitution in consumption is normalized to one without loss of generality.

The marginal propensity to consume depends positively on (i) the share of non-asset holders $\lambda$ and (ii) the elasticity of labor supply $\varphi$. The impact of the former on the marginal propensity can be rationalized by the dependence of total consumption upon consumption of agents who do not hold assets and are unable to smooth consumption, and are therefore sensitive to changes in current income. With regards to the labor supply elasticity, note that inelastic labor supply implies small variations in hours (and output) and is associated with large variation in real wage and hence consumption of non-asset holders. Consequently, the aggregate propensity to consume depends finally on income distribution, which changes as aggregate income and the wage rate change; this gives the model a distinctly Keynesian flavor. Together with the condition that consumption equal output $c_{t}=y_{t}$, equation (1) leads to a "Keynesian cross"-type diagram and the standard IS equation in case $\partial c / \partial y<1$ (see the thick black line labelled "K" in Figure 1).

${ }^{10}$ This approximation only holds if steady-state consumption shares of the two types are equal, that is asset income is zero in steady-state. This is insured by assuming a fixed cost of production whose share in steady-state output is equal to net markup and makes steady-state profits zero.

${ }^{11}$ We thank Jordi Gali for having suggested the Keynesian cross interpretation. 
However, note that the marginal propensity to consume out of current income (output) $\partial c / \partial y$ can become greater than one. This case, which we label "non-Keynesian", occurs when enough agents consume their wage income $w_{t}$ ( $\lambda$ high) and/or wage is sensitive enough to real income $y_{t}(\varphi$ high $)$, more precisely when:

$$
\lambda>\lambda^{*}=\frac{1}{1+\varphi /(1+\mu)} .
$$

Aggregate marginal propensity to consume (again, for a given $c_{S}$ ) can be larger than one since non-asset holders consume all their current income given by the real wage, which is instead related to total output (income) more than one-to-one (and the more so, the more inelastic is labor supply).

We plot (1) in this case along with the $c=y$ schedule in the "Non-Keynesian cross" in Figure 1, where an increase in the real interest rate moves the (1) schedule rightward (by intertemporal substitution) leading to higher consumption and output.

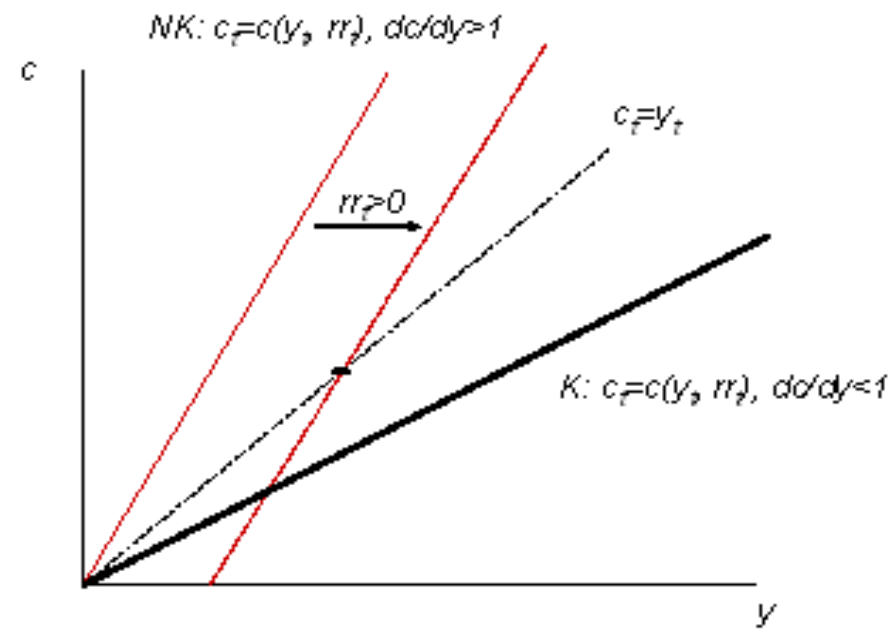

Figure 1. Keynesian and Non-Keynesian Crosses.

An immediate implication of (2) is that the slope of the aggregate IS curve changes sign. Consumption of asset holders is related to total output, combining (1) with $c_{t}=y_{t}$, by:

$$
c_{S, t}=\delta y_{t}, \text { where } \delta \equiv 1-\frac{\lambda}{1-\lambda} \frac{\varphi}{1+\mu} .
$$

Note that $\delta$ becomes negative when $\partial c / \partial y>1$, that is precisely when (2) holds. Consumption of asset holders can be negatively related to total output since an increase in demand can only be satisfied by movements of (as opposed to movements along) the labor supply schedule when enough people hold no assets and labor supply is inelastic enough. But the necessary rightward shift of labor supply can only come from a negative income effect on consumption of asset holders. This negative income effect is ensured in general equilibrium by a potential fall in dividend income. Note that asset holders have in their portfolio $(1-\lambda)^{-1}$ shares: if total profits fell by one 
unit, dividend income of one asset holder would fall by $(1-\lambda)^{-1}>1$ units. ${ }^{12}$ The potential decrease in profits is a natural result of inelastic labor supply, since the increase in marginal cost (real wage) would more than outweigh the increase in sales (hours). Therefore, the mechanism relies on consumption of asset holders being sensitive to unforeseen changes in the money-value of their assets $^{13}$.

Substituting (3) into the Euler equation we obtain the aggregate IS curve:

$$
y_{t}=E_{t} y_{t+1}-\delta^{-1}\left[r_{t}-E_{t} \pi_{t+1}\right] \text {. }
$$

Direct inspection of (4) suggests the impact that limited asset market participation has on the dynamics of a standard business cycle model through modifying the elasticity of aggregate demand to real interest rates $\delta^{-1}$ in a non-linear way. For high enough participation rates $\lambda<\lambda^{*}$ (where the latter is given by (2)) we are in a "Keynesian" region, whereby real interest rates restrain aggregate demand. As $\lambda$ increases towards $\lambda^{*}$, the sensitivity to interest rates increases in absolute value, making policy more effective in containing demand. However, once $\lambda$ is above the threshold $\lambda^{*}$, we move to the "non-Keynesian" region where increases in real interest rates become expansionary (see also Figure 1). As $\lambda$ tends to its upper bound of $1, \delta^{-1}$ decreases towards zero, that is policy is ineffective when nobody holds assets. We will call "non-Keynesian" an economy in which participation in asset markets is limited enough such that $\delta<0$. Finally, note that the only way for $\delta$ to be independent of $\lambda$ is for $\varphi$ to be zero, that is labor supply of asset holders be infinitely elastic. In this case, consumption of all agents is independent of wealth, making the heterogeneity introduced in this paper irrelevant.

\section{A. "Inverted Taylor Principle" and Optimal Passive Monetary Policy}

In this section, we discuss the implications of our theoretical findings for macroeconomic stability and welfare. We will argue that when the IS curve's slope changes sign, optimal policy switches endogenously from passive to active; much like Fed's policy has changed in the early 1980s.

To be able to analyze monetary policy and draw normative conclusions, we need to complement the IS curve (4) by an equation for inflation dynamics and one for interest rate setting in order to close our model. As regards inflation dynamics, we follow an enormous recent literature and assume that prices are sticky (see Woodford, 2003, for a comprehensive

\footnotetext{
${ }^{12}$ In the standard model, all agents hold assets, so this mechanism is completely irrelevant. Any increase in wage exactly compensates the decrease in dividends, since all output is consumed by asset holders.

${ }^{13}$ However, it is important to note that this negative income effect does not mean that for a given increase in output, the consumption of asset holders will necessarily decrease in equilibrium. Moreover, precisely due to the negative income effect making asset holders willing to work more, actual profits may not fall, since hours will increase by more and marginal cost by less. In fact, for certain configurations of shocks and parameters, the equilibrium of our model implies more procyclical profits than the standard New Keynesian model with countercyclical markups. See Bilbiie (2003) for further discussion.
} 
studies of this framework). This provides a by now well-understood, simple benchmark for the analysis of monetary policy and makes our model easy to compare to other theories. Assume for instance that prices are sticky $\grave{a}$ la Calvo, whereby a history-independent fraction of firms $\theta$ is unable to reset prices. This gives rise to the well-known "New Phillips curve" relating actual to expected inflation and marginal cost: $\pi_{t}=\beta E_{t} \pi_{t+1}+\psi m c_{t}$, where $\beta$ is the discount factor and $\psi \equiv(1-\theta)(1-\theta \beta) / \theta$. In the absence of any disturbances breaking this link, marginal cost and output $y_{t}$ are related by: $m c_{t}=\chi y_{t}$, where $\chi \equiv 1+\varphi /(1+\mu)$. We do break this link (following CGG (1999) or Woodford (2003)), by assuming the presence of "cost-push" shocks ${ }^{14}$ $u_{t}$ such that $m c_{t}=\chi\left(y_{t}+u_{t}\right)$. Hence, inflation $\pi_{t}$ is related to its expected value and output $y_{t}$ by $^{15}$ :

$$
\pi_{t}=\beta E_{t} \pi_{t+1}+\kappa\left(y_{t}+u_{t}\right), \text { where } \kappa \equiv \psi \chi
$$

The model is closed by specifying how monetary policy is conducted. We will study two alternative settings: a simple interest rate rule, and optimal (welfare-maximizing) monetary policy. For the former, we consider rules involving a response to expected inflation, as done for example by CGG (2000) (capturing the idea that central banks respond to a larger set of information than merely the current inflation rate):

$$
r_{t}=\phi_{\pi} E_{t} \pi_{t+1}
$$

We abstract from interest rate smoothing and a response to output. This specification provides simpler determinacy conditions and makes the mechanism behind the theoretical results fully transparent. Such extensions are incorporated later in the more general model used for estimation.

An immediate implication of the change in the sign of $\delta^{-1}$ is that the stabilization properties of monetary policy are inverted. Recent research in monetary policy argues that in order to ensure macroeconomic stability in the standard, full-participation framework, monetary policy needs to increase nominal rates systematically more than one-to-one for a given increase in inflation (be "active"). If nominal interest rates are set according to (6), when $\delta^{-1}>0$ the response coefficient needs to fulfill what Woodford (2001) has labelled "the Taylor principle": $\phi_{\pi}>1$. This ensures equilibrium determinacy when prices are set on a forward-looking basis. ${ }^{16}$ Intuitively, a sunspot shock (increasing expected inflation for no fundamental reason) has no effects since by triggering an increase in the real rate, it leads to a fall in aggregate demand (from

${ }^{14}$ These can represent variations in the price markups coming from time-varying elasticity of substitution between intermediate goods, variations in the degree of market power in the labor market, distortionary taxation or other time-varying inefficiency wedges - see Woodford (2003, Chapter 6) for details.

${ }^{15}$ The New Keynesian Phillips curve is not influenced by the presence of non-asset holders only because steady-state profit income is zero. This is not the case in the more general set-up, but the differences are not crucial for the mesage of our paper.

${ }^{16}$ Formally, one puts together equations (4) and (5), having replaced (6) and looks at the eigenvalues of this dynamic system. Since both inflation and output are forward-looking variables, both eigenvalues need to be larger than one for equilibrium to be determinate. When this is not the case, equilibrium is indeterminate, and sunspot shocks have real effects. 
(4)). This instead means that actual inflation will decrease (by the Phillips curve), contradicting the initial non-fundamental expectation.

Clearly, in the non-Keynesian case $\delta<0$, an "Inverted Taylor principle" holds; in order to ensure stability, monetary policy needs to be passive: ${ }^{17}$

$$
\phi_{\pi}<1
$$

In the Non-Keynesian economy $(\delta<0)$, a non-fundamental increase in expected inflation generates an increase in the output gap today if the policy rule is active $\left(\phi_{\pi}>1\right)$ as can be seen from (4). If a Phillips curve holds, this means that inflation today increases, making the initial non-fundamental beliefs self-fulfilling. How does a passive policy rule ensure equilibrium determinacy? A non-fundamental increase in expected inflation causes a fall in the real interest rate, a fall in the output gap today by (4), and deflation, contradicting to the initial expectation. At a more micro level, the transmission is as follows: The fall in the real rate leads to an increase in consumption of asset holders, and an increase in the demand for goods; but note that these are now partial effects. To work out the overall effects one needs to look at the component of aggregate demand coming from non-asset holders and hence at the labor market. The partial effects identified above would cause an increase in the real wage (and a further boost to consumption of non-asset holders) and a fall in hours. Increased demand, however, means that (i) some firms adjust prices upwards, bringing about a further fall in the real rate (as policy is passive); (ii) the rest of firms increase labor demand, due to sticky prices. Note that the real rate will be falling along the entire adjustment path, amplifying these effects. But since this would translate into a high increase in the real wage (and marginal cost) and a low increase in hours, it would lead to a fall in profits, and hence a negative income effect on labor supply. The latter will then not move, and no inflation will result, ruling out the effects of sunspots. This happens when asset markets participation is limited "enough" in a way made explicit by (2).

How does the presence of non-asset holders alter the optimal design of monetary policy rules in the simple model sketched above? To address this question we use a welfare-based quadratic loss function derived for our model with two types of agents (a complete derivation for a more general case is detailed in Bilbiie, 2003). We make a series of assumptions common in the literature that render these second-order approximation techniques valid (see Woodford, 2003). Firstly, we assume that efficiency of the steady state is obtained by appropriate fiscal instruments inducing marginal cost pricing in steady state (subsidies for sales at a rate equal to the stead-state net mark-up financed by lump-sum taxes on firms). Since this policy makes steady-state profit income zero, the steady-state is also equitable: steady-state consumption shares of the two agents are equal, making aggregation much simpler. This ensures consistency with the model outlined

\footnotetext{
${ }^{17}$ This condition is necessary and sufficient if the Philips curve reads merely: $\pi_{t}=y_{t}$. With the forward-looking Philips curve, this condition is sufficient under somehwat more restrictive conditions on $\lambda$. For a full-fledged determinacy discussion, see Bilbiie (2003), where sufficient conditions are also provided. He shows that this result holds generically, that is for rules responding to current inflation, as well as for rules responding to output gap under more restrictive conditions.
} 
above. ${ }^{18}$ Secondly, we assume that the social planner maximizes (the present discounted value of) a convex combination of the utilities of the two types, weighted by the mass of agents of each type. ${ }^{19}$ The quadratic approximation of the objective function around the efficient flexible-price equilibrium ${ }^{20}$ yields:

$$
\begin{aligned}
\mathbf{U}_{t} & =-\frac{1}{2} \frac{\varepsilon}{\psi} E_{t} \sum_{i=t}^{\infty}\left\{\alpha y_{t+i}^{2}+\pi_{t+i}^{2}\right\} \\
\alpha & =\frac{1+\varphi}{1-\lambda} \frac{\psi}{\varepsilon}
\end{aligned}
$$

Note that when $\lambda=0$, the weight on output stabilization collapses to the standard one: $\alpha=1+\varphi$. In general, the relative weight on output is increasing in the share of non-asset holders. When the share of non-asset holders tends to one, the relative weight on output stabilization tends to infinity. Hence, the presence of non-asset holders modifies the trade-off faced by the monetary authority. The intuition for this result is simple: relative price dispersion (related here linearly to squared inflation) erodes aggregate profit (dividend) income for given levels of output and marginal cost. Given that only a fraction of $(1-\lambda)$ receives profit income, when this fraction tends to zero, the welfare-based relative weight on inflation (price dispersion) also tends to zero.

The optimal discretionary rule $\left\{r_{t}^{o}\right\}_{0}^{\infty}$ is found by minimizing $-\mathbf{U}_{t}$ taking as a constraint the IS-AS system, and re-optimizing every period..$^{21}$ Note that by usual arguments, this equilibrium will be time-consistent. This is, up to interpretation of the solution, isomorphic to the standard problem in CGG, 1999. Hence, for brevity, we skip solution details available elsewhere and go to the result:

$$
y_{t}=-\frac{\kappa}{\alpha} \pi_{t}
$$

Policy needs to conform the same principle as in the standard model: when inflation increases (decreases) the central bank has to act in order to contract (expand) demand. Assuming an AR(1) process for the cost-push shock $E_{t} u_{t+1}=\rho_{u} u_{t}$ for simplicity, we obtain the following reduced

\footnotetext{
${ }^{18}$ Note, however, that since steady-state consumption shares are equal we do not need to assume increasing returns. Under these assumptions, the reduced-form coefficients simply modifiy as follows: $\chi^{o}=1+\varphi$ and $\delta^{o}=1-\varphi \lambda /(1-\lambda)$.

${ }^{19}$ This is consistent with our view that limited participation to asset markets comes from constraints and not preferences, since in the latter case maximizing intertemporally the utility of non-asset holders would be hard to justify on welfare grounds. However, note that for the discretionary Markov equilibrium studied here, this choice makes no difference since terms from time $t+1$ onwards are treated parametrically in the maximization and the time- $t$ objective function is identical.

${ }^{20}$ Note that since we abstract from shocks other than cost-push, the efficient level of output is zero, and output is equal to the output gap defined with reference to this efficient level.

${ }^{21}$ To keep things simple, we focus on the discretionary, and not fully optimal (commitment) solution to the central banker's problem. This case can be argued to be more realistic in practice, as do CGG (1999).
} 
forms for inflation and output from the aggregate supply curve:

$$
\pi_{t}=\alpha \Upsilon u_{t} ; y_{t}=-\kappa \Upsilon u_{t},
$$

where $\Upsilon \equiv \kappa\left[\kappa^{2}+\alpha\left(1-\beta \rho_{u}\right)\right]^{-1}$. Substituting the expressions given by (10) into the IS curve, we obtain the implicit instrument rule consistent with optimality:

$$
\begin{aligned}
r_{t}^{o} & =\phi_{\pi}^{o} E_{t} \pi_{t+1}, \\
\phi_{\pi}^{o} & =\left[1+\frac{\delta \kappa}{\alpha} \frac{1-\rho_{u}}{\rho_{u}}\right]
\end{aligned}
$$

The optimal response to inflation is decreasing in the share of non-asset holders $\frac{\partial \phi_{\pi}^{o}}{\partial \lambda}<0$.

Three implications regarding optimal policy are worth stressing. Firstly, since $\alpha$ is increasing in $\lambda$, in an economy with limited asset market participation optimal policy results in greater inflation volatility and lower output gap volatility than in a full participation economy $(\lambda>0)$. This can be seen directly from (10). Optimal policy in this case requires more output stabilization at the cost of accommodating inflationary pressures. Secondly, in a non-Keynesian economy $(\delta<0)$, the implied instrument rule for optimal policy is passive $\phi_{\pi}^{o}<1$. In order to contract demand when inflation increases as required by (9), the central bank must move nominal rates such that the real rate decreases. Thirdly, the optimal response to inflation switches from passive to active when the degree of asset markets participation changes such that $\delta$ changes sign from negative to positive. This suggests that the response of the Fed to inflation may have changed endogenously from passive to active in the late 1970s, due to the change in asset market participation.

In summary, we have outlined a theory that indicates the desirability of passive interest rate rules when part of the agents do not participate in asset markets and do not smooth consumption. This desirability obtains for two related reasons: (i) ensuring equilibrium determinacy and ruling out potentially welfare-damaging sunspot fluctuations and (ii) welfare maximization. Moreover, we have suggested that when the degree of asset market participation changes, optimal policy should also change. In particular, the optimal response to inflation switches endogenously from passive to active when $\delta$ changes sign. If in the 1970s U.S. asset markets participation was exceptionally limited such that the IS curve's slope had the "wrong" sign, our model suggests that monetary policy during the period was better than conventional wisdom dictates. We now provide evidence supporting this view.

\section{EMPIRICAL EVIDENCE}

In this section, we provide empirical evidence for the discussed hypothesis. First, we present institutional evidence for the change in U.S. asset market participation in the early 1980s. Further, we estimate a version of our model with a richer dynamic structure on U.S. data by utilizing Bayesian structural estimation techniques, ${ }^{22}$ distinguishing between the pre-Volcker

\footnotetext{
${ }^{22}$ Bayesian estimation has several advantages compared to classical Maximum Likelihood (ML) methods. In particular, estimating DSGE models with classical ML generate in many cases very
} 
and Volcker-Greenspan samples. We show that, consistently with the institutional evidence, the fraction of agents participating in asset markets has changed between the two periods, causing a significant change in the sign of the sensitivity of aggregate demand to interest rates. As we argued before, we believe that this is an important and so far neglected part of the "Great Inflation" story. Consistently with the results of other papers, we also find that the response of monetary policy changed from passive to active between the two samples, several other structural changes detailed below took place and, importantly, that the distribution of the shocks has changed. Finally, we investigate whether the changes in "structure" (deep parameters) or "shocks" (stochastic environment) have been paramount in driving the changes in U.S. macroeconomic outcomes.

\section{A. Institutional Evidence for Change in Asset-Market Participation}

In this section, we put together some background institutional evidence suggesting that the U.S. economy in the mid-1960s and 1970s was characterized by lower asset market participation as compared to the post-1980 period. The change in asset markets participation is problematic to pin down: there is to our knowledge no empirical study documenting such a change, let alone that data availability problems abound. ${ }^{23}$ However, there is institutional information to support our view that financial markets changed fundamentally in the early 1980s, leading to more widespread asset holding. A thorough discussion of financial reform in the early 1980s, its causes and consequences, can be found in Cargill and Garcia (1985). Mishkin (1991) and references quoted therein provide a comprehensive review of financial market developments in this period. For a variety of reasons having to do with excessive regulation, in the 70s, asset holding was limited and most assets held by small savers were not making interest linked to market interest rates. In a nutshell, two restrictions were prevalent (i) Regulation Q, that is, limits on interest paid by commercial banks to allow Savings and Loans Institutions (S\&Ls) to pay slightly more interest, became binding around 1965 as market interest rates rose to unprecedented level, and no interest was being paid on checking accounts; (ii) discouragement of other financial market instruments. In 1970, the Treasury was convinced to raise minimum denomination on T-bills to $\$ 10,000$, and bank holding companies and corporations not to issue small-denominated debt. Hence, small savers were not making the market interest rate, which was well recognized at least by Congress (and was to trigger a legislative response).

This situation changed in 1980, owing to legislators" response via deregulation and to markets" response via financial innovation, causes which are sometimes hard to disentangle. On the latter point, Wenninger (1984) and Silber (1983) list literally hundreds of instruments created by financial innovation, most of them gaining wide usage in the post-1980 period ${ }^{24}$. On the former point, 1980 saw the adoption of the Depository Institutions Deregulation and Monetary

flat likelihood functions. This makes the identification of the global optimum difficult.

${ }^{23}$ Consumer Expenditure Survey data on asset holdings starts only in 1984, while the Survey of Consumer Finances over-samples high-wealth households (making it inappropriate for our exercise). The Panel Study of Income Dynamics (PSID) contains wealth data with a five-year frequency only starting in 1984 . Some wealth information is contained in the family files previous to 1984 .

${ }^{24}$ Among them: (i) consumer assets (saver certificates, Money Market (MM) mutual funds, 
Control Act (DIDMCA), followed in 1982 by the Garn-St Germain Depository Institutions Act, which reinforced such de-regulatory provisions. Among the most important provisions, the DIDMCA introduced a phaseout of Regulation Q, let Savings \& Loans Institutions make other types of loans and engaged in other activities, approved many of the new instruments mentioned above nationwide, eliminated usury ceilings on mortgage loans and some business loans, and provided uniform access to Fed reserve facilities for all depository institutions. ${ }^{25}$

To give just an example (see Mishkin, 1991) of the magnitude of the change in financial markets: total assets of Money Market mutual funds increased from 4 billion in 1978 to 230 billion in 1982, and NOW accounts increased from 27 to 101 billion from 1980 to 1982. Moreover, the early 1980s saw the advent of Individual Retirement Accounts (IRAs), an important new saving vehicle. The introduction and spreading of new financial instruments and the elimination of ceilings on deposit rates (re-)linked saving decisions to market interest rates, which justifies our assumption about the change in asset market participation across the two periods. This is further supported by evidence from the 1983 Survey of Consumer Finances data on asset holdings and net worth. Table 8 therein shows that from 1970 to 1983, the percentage of families holding certificates of deposit changed from 8 to 20, and for money market accounts from 0 to 14. Table 5 in the Second report shows that the percentage of families with net worth less than $\$ 10,000$ changed from 56 percent to 38 percent (see Wolff and Caner, 2002, for a careful study of asset-poverty dynamics using post-1984 PSID data). Finally, the New York Stock Exchange reports that the proportion of U.S. families holding shares has almost doubled over the period 1975-1985 (see NYSE, 1986). Duca (2001) presents further evidence that the decline in transaction costs (e.g., mutual fund loads, brokerage fees, and cost of exchange-traded funds) led to more widespread asset holding since the early 1980s. Jones (2002) provides evidence that commissions and spreads for shares at the NYSE have declined abruptly in the late 1970s and early 1980s (for example, one-way transaction costs declined from about 1.20 percentage points in the mid-70s to 0.60 in the early 80s). Corroborated with the phasing out of Regulation Q, such that savings accounts started actually making the market interest rate, all these arguments complete our justification for believing that the U.S. economy before 1980 was marked by relatively more

ceiling-free MM certificates, Negotiable Order of Withdrawal (NOW) and super-NOW accounts, MM deposit accounts, tax-exempt All-Savers certificates); (ii) consumer credit and mortgages (equity access accoutns, secondary mortgage market, floating-rate loans, leasing and flexible credits, variable rate mortgages and consumption installment loans); (iii) Treasury securities (variable rate bonds, adjustable-rate Fannie MAE, etc.); (iv) Tax-exempt securities; e. corporate bonds (deep-discound bonds, zero coupon and variable-rate bonds, bonds with warrants and interest rate swaps); (v) futures and options on cash market instruments, stock market indices, etc. ${ }^{25}$ The basic purpose of the DIDMCA is stated clearly in the first paragraph: "(a) The Congress hereby finds that: (i) limitations on the interest rates which are payable on deposits and accounts discourage persons from saving money, create inequities for depositors, impede the ability of depository institutions to compete for funds, and have not achieved their purpose of providing an even flow of funds for home mortgage lending; and (ii) all depositors, and particularly those with modest savings, are entitled to receive a market rate of return on their savings as soon as it is economically feasible for depository institutions to pay such rate." 
limited asset markets participation.

In summary, we have presented evidence that: (i) the vast majority of assets classified now as wealth simply did not exist prior to the early 1980s; (ii) of those that existed, some such as checking accounts were earning zero interest rates, others as saving accounts were not making the market interest rate due to Regulation Q being binding and yet others (treasury bills) were subject to quantitative restrictions discouraging their holding; (iii) house equity could not be used for consumption-smoothing purposes since there was no secondary mortgage market and consumer credit only developed during this period; (iv) shareholding changed significantly. We have argued that a significant structural change occurred in the early 1980s, the timing of which can be traced by Congress-adopted legislation dealing precisely with these issues (namely, the DIDMCA and the Garn-St Germain Act).

\section{B. Bayesian Estimation of Structural Model}

In this section we fit a general version of our model to quarterly U.S. data on real GDP, the annualized quarterly CPI inflation, and the quarterly average of the overnight federal funds rate, expressed in units of percent per year. ${ }^{26}$ To make our results comparable with previous studies we divide the data set into two subsamples. The pre-Volcker sample ${ }^{27}$ contains quarterly data from 1965:IV to 1979:III, while the Volcker-Greenspan sample reaches from 1983:I to 2002:I. In line with the related literature, we exclude the "Volcker disinflation" period from the sample. To capture the underlying dynamics in macroeconomic variables, we extend our baseline model to allow for less restrictive endogenous persistence. In particular, we introduce, in line with the empirical literature, habit persistence in consumption and price-indexation into the model, while monetary policy formulation is characterized by a more general Taylor rule with interest rate smoothing. ${ }^{28}$ The model is presented in detail in the Appendix.

The canonical (or reduced-form) representation of the estimated model is basically indistinguishable from the extended version of the model estimated by LS (2004). However, the introduction of non-asset holders changes the underlying elasticities and, in contrast to the standard literature, allows for a positive IS-curve slope. Namely, the corresponding IS-curve with

${ }^{26}$ The data on real GDP (GDPC1) is from the Bureau of Economic Analysis (BEA), while inflation is the quarterly annualized percentage change of CPI-U from the Bureau of Labor Statistics (BLS), and the nominal interest rate is the average Federal Funds Rate (FYFF) in percentage points.

${ }^{27}$ The beginning of the estimation period is dictated by the behavior of monetary policy, as only after 1965 did the federal funds rate act as a primary instrument of monetary policy - see Meulendyke (1989).

${ }^{28}$ The absence of endogenous persistence from the model generally biases estimates towards parameter constellations which imply indeterminacy, since ceteris paribus indeterminacy implies more endogenous persistence (see LS, 2004 for a discussion of indeterminacy and endogenous persistence in DSGE models). The main results of our paper are confirmed, however, even in a simpler version of the model without habit formation, price indexation, and interest rate smoothing (results are available upon request). 
habit persistence and limited asset market participation has the following form:

$$
y_{t}=\frac{\Gamma_{1}}{\Gamma_{1}+\Gamma_{2}} E_{t} y_{t+1}+\frac{\Gamma_{2}}{\Gamma_{1}+\Gamma_{2}} y_{t-1}-\frac{1-\gamma}{\Gamma_{1}+\Gamma_{2}}\left(r_{t}-E_{t} \pi_{t+1}\right)+g_{t},
$$

where

$$
\Gamma_{1}=1-\frac{\lambda}{1-\lambda} \frac{\varphi}{1+\mu}\left[1+\frac{\gamma \mu}{1+\varphi(1-\gamma)}\right] ; \Gamma_{2}=\gamma\left[1-\frac{\lambda}{1-\lambda} \frac{\varphi}{1+\varphi(1-\gamma)}\right]
$$

Notice that $\gamma$ captures the degree of habit persistence in consumption, and influences the threshold level of $\lambda$ beyond, which the slope of the IS curve changes sign. ${ }^{29}$ In order to perform the estimation exercise, we enrich the stochastic structure of the model following LS (2004) and augment the IS-curve with an AR(1) "aggregate demand" shock $g_{t}=\rho^{g} g_{t-1}+\varepsilon_{t}^{g}$. Similarly, we add to the New-Keynesian Phillips curve with limited asset market participation and price indexation an $\operatorname{AR}(1)$ "supply" shock $z_{t}=\rho^{z} z_{t-1}+\varepsilon_{t}^{z}$. The Phillips curve is:

$$
\pi_{t}=\frac{\beta}{1+\beta \omega} E_{t} \pi_{t+1}+\frac{\omega}{1+\beta \omega} \pi_{t-1}+\psi\left(1-\gamma+\frac{\varphi}{1+\mu}\right) y_{t}-\psi \frac{\gamma}{1-\gamma} y_{t-1}+z_{t},
$$

where $\omega$ is the degree of price indexation, and $\psi \equiv(1-\theta)(1-\theta \beta) / \theta$. Importantly, notice that $\varepsilon_{g, t}$ is a non-structural reduced-form shock, and represents a convolution of shocks to technology, government spending, preferences, and other shocks apart from cost-push. As discussed for example in Woodford (2003), all these shocks will also have an immediate, direct impact on the Phillips curve. On the contrary, there exists shocks that can potentially move the Phillips curve without having any impact on the IS curve (the so-called "cost-push" shocks). We model this, following LS (2004) by assuming that all potential shocks that move the IS curve, summarized by $\varepsilon_{g, t}$ also influence influence the Phillips curve; that is, in the estimation we allow for a non-zero correlation $\rho^{g z}$ between the innovations $\varepsilon_{g, t}, \varepsilon_{z, t}$. Correspondingly, in what follows the standard deviations of the reduced-form innovations are defined as $\sigma^{\varepsilon_{g}}, \sigma^{\varepsilon_{z}}$, while the standard deviations of the structural shocks, say $e_{g}$ and $e_{z}$ can be found by standard Choleski-decomposition algebra: $\sigma^{e_{g}}=\sigma^{\varepsilon_{g}}$ and $\sigma^{e_{z}}=\sigma^{\epsilon_{z}} \sqrt{1-\left(\rho^{g z}\right)^{2}}$. Note that the "supply" shock to the Phillips curve will be a linear combination of the "IS" shock $e_{g}$ and the cost-push shock $e_{z}$.

The model is closed by a general version of a Taylor rule, incorporating interest rate smoothing:

$$
r_{t}=\phi_{r} r_{t-1}+\left(1-\phi_{r}\right)\left(\phi_{\pi} E_{t} \pi_{t+1}+\phi_{x} y_{t}\right)+\varepsilon_{t}^{r}
$$

where the monetary policy shock $\varepsilon_{t}^{r}$ is white noise.

${ }^{29}$ For $\gamma=0$, this reduces to the economy without habits in the first section since $\Gamma_{2}=0$ and $\Gamma_{1}=\delta$. If $\lambda=0$, this boils down to a standard economy with habits: $\Gamma_{1}=1, \Gamma_{2}=\gamma$. 
Table 1. Prior Distributions for DSGE Model Parameters

\begin{tabular}{llcccc}
\hline & & \multicolumn{2}{c}{ Pre-Volcker } & \multicolumn{2}{c}{ Volcker-Greenspan } \\
\hline Name & Density & Mean & Std. Deviations & Mean & Std. Deviations \\
\hline$\lambda$ & Beta & 0.35 & 0.10 & 0.30 & 0.10 \\
$\varphi$ & Gamma & 3.00 & 0.50 & 3.00 & 0.50 \\
$\gamma$ & Beta & 0.50 & 0.20 & 0.50 & 0.20 \\
$\omega$ & Beta & 0.50 & 0.20 & 0.50 & 0.20 \\
$\phi_{\pi}$ & Gamma & 0.50 & 0.50 & 2.00 & 0.50 \\
$\phi_{y}$ & Gamma & 0.25 & 0.15 & 0.25 & 0.15 \\
$\phi_{r}$ & Beta & 0.25 & 0.25 & 0.25 & 0.25 \\
$\pi^{*}$ & Gamma & 4.00 & 2.00 & 4.00 & 2.00 \\
$r^{*}$ & Gamma & 2.00 & 1.00 & 2.00 & 1.00 \\
\hline$\rho^{g}$ & Beta & 0.70 & 0.10 & 0.70 & 0.10 \\
$\rho^{z}$ & Beta & 0.70 & 0.10 & 0.70 & 0.10 \\
$\sigma^{\epsilon_{g}}$ & Inverse Gamma & 0.38 & 0.20 & 0.38 & 0.20 \\
$\sigma^{\epsilon_{z}}$ & Inverse Gamma & 1.00 & 0.52 & 1.00 & 0.52 \\
$\sigma^{\epsilon_{r}}$ & Inverse Gamma & 0.31 & 0.16 & 0.31 & 0.16 \\
$\rho^{g z}$ & Truncated Normal & 0.00 & 0.10 & 0.00 & 0.10 \\
\hline
\end{tabular}

Notes: The prior for $\rho^{g z}$ is truncated to ensure that the correlation lies between -1 and 1.

The theoretical model is a system of log-linearized equations. To connect it to the available dataset, we will undertake the following transformations. First, we remove the smooth trend from the real U.S. GDP series using the Hodrick-Prescott (HP) filter. Then, we connect the vector of endogenous variables $s_{t}=\left[y_{t}, \pi_{t}, r_{t}\right]$ to the vector of observable variables $o_{t}$ via the following measurement equations:

$$
o_{t}=\left[\begin{array}{c}
0 \\
\pi^{*} \\
r^{*}+\pi^{*}
\end{array}\right]+\left[\begin{array}{lll}
1 & 0 & 0 \\
0 & 4 & 0 \\
0 & 0 & 4
\end{array}\right] s_{t},
$$

where $\pi^{*}$ and $r^{*}$ are annualized steady-state inflation and real interest rate in percentage terms. The measurement equation together with the structural equations and the shock processes form the state space representation of the observables $o_{t}$. The parameter vector has the form: $\Phi=\left[r^{*}, \pi^{*}, \lambda, \varphi, \mu, \gamma, \omega, \beta, \phi_{\pi}, \phi_{y}, \phi_{r}, \rho^{g}, \rho^{z}, \sigma^{\varepsilon_{g}}, \sigma^{\varepsilon_{z}}, \sigma^{\varepsilon_{r}}, \rho^{g z}\right]$. We use the Kalman-Filter to evaluate the corresponding likelihood function $L\left(Y^{T} \mid \Phi\right)$ of the state space representation of the model. For the estimation, we adopt a Bayesian approach and combine the likelihood of the model with a prior density $p(\Phi)$. By neglecting any constants the posterior density function has the following form:

$$
p(\Phi \mid Y)=L\left(Y^{T} \mid \Phi\right) p(\Phi) .
$$

There is no closed form solution for the posterior $p(\Phi \mid Y)$, so we calculate the posterior distribution of the parameters using the Metropolis-Hastings sampling algorithm. Before discussing the results, we present the choice of our priors. 


\section{Prior distributions}

A number of parameters were kept fixed from the start. First, notice that by definition, the discount factor $\beta$ equals $\left(1+r^{*} / 100\right)^{-1 / 4}$. We also set the steady state mark up $\mu$ to 0.2 and the degree of nominal rigidity $\theta$ to 0.75 . Both values are frequently chosen in calibration exercises. Table 1 provides details about the set of prior distributions for the remaining parameters.

In most of the cases, we choose the same priors for the parameters for both, the pre-Volcker and Volcker-Greenspan period. We deviated from this strategy only for the parameters capturing the share of liquidity constraint agents $\lambda$ and the coefficient governing the interest rate response to changes in expected inflation $\phi_{\pi}$. There is overwhelming empirical evidence that the interest rate response to inflation in the Fed's monetary rule was below one for the pre-Volcker period. ${ }^{30}$ Accordingly, we chose the corresponding prior to follow a gamma distribution with mean 0.5 for the pre-Volcker period, while we set the prior mean to be equal to 2 for the Volcker-Greenspan era. By setting the standard deviation equal to 0.5 , we chose a wide confidence interval for this parameter. Furthermore, in line with the institutional evidence presented in the previous section, we set the mean of the distribution describing the share of liquidity constraint agents to a slightly higher value in the pre-Volcker era than in the Volcker-Greenspan period. In particular, we chose as a prior a beta distribution with mean 0.35 for the pre-Volcker period, while the mean of the prior-distribution is assumed to be slightly lower at 0.30 following Volcker's inauguration. We believe that the choice of different priors is justified not only because, as discussed in the theoretical part of the model, it is required to ensure that the estimated model is determinate, but also given the institutional evidence provided in the previous subsection.

For the inverse of the elasticity of labor supply $\varphi$, we have chosen a gamma distribution with mean 3.00 and standard deviation 0.50 in both periods. The confidence interval for $\varphi$ entails the values generally chosen in calibration exercises and consistent with microeconomic evidence (see for example Domeij and Floden, 2004 ). The priors for the habit persistence and the price indexation coefficients are both assumed to have a beta distribution with mean 0.5 and a standard deviation of 0.2 . The prior for the output response coefficient in the monetary rule is assumed to have a gamma distribution with mean 0.25 and standard deviation 0.10 . Similarly, the prior for the interest rate smoothing coefficient follows a beta distribution with mean 0.25 and standard deviation 0.25 .

\section{Estimation results}

We present the estimation results in Table 2. Our hypothesis that the slope of the IS-curve changed sign in the 1980s is supported by the outcome. The posterior in both cases indicates that our prior for the share of non-asset holders was rather too low (in case of the pre-Volcker) or too high (in case of the Volcker-Greenspan era). In particular, the posterior mean of the share of non-asset holders $\lambda$ falls from 0.44 in the pre-Volcker period to 0.24 in the Volcker-Greenspan

${ }^{30}$ This is true for studies using the same data as ours, but not for studies such as Orphanides (2002), which use data that were available at the time to policymakers. Our choice of prior is in line with our use of historical data. 
Table 2. Bayesian Estimation Results

\begin{tabular}{lcccc}
\hline & \multicolumn{2}{c}{ Pre-Volcker } & \multicolumn{2}{c}{ Volcker-Greenspan } \\
\hline Parameter & Mean & 90 percent interval & Mean & 90 percent interval \\
\hline$\lambda$ & 0.44 & {$[0.38-0.51]$} & 0.24 & {$[0.17-0.31]$} \\
$\varphi$ & 2.98 & {$[2.27-3.63]$} & 2.62 & {$[1.90-3.36]$} \\
$\gamma$ & 0.43 & {$[0.24-0.64]$} & 0.36 & {$[0.27-0.45]$} \\
$\omega$ & 0.54 & {$[0.34-0.74]$} & 0.07 & {$[0.01-0.13]$} \\
IS-slope & 1.25 & & -0.65 & \\
$\phi_{\pi}$ & 0.52 & {$[0.42-0.62]$} & 2.39 & {$[2.09-2.70]$} \\
$\phi_{y}$ & 0.10 & {$[0.05-0.15]$} & 0.07 & {$[0.01-0.13]$} \\
$\phi_{r}$ & 0.01 & {$[0.00-0.02]$} & 0.66 & {$[0.57-0.75]$} \\
$\pi^{*}$ & 4.54 & {$[3.11-6.02]$} & 3.26 & {$[2.48-4.10]$} \\
$r^{*}$ & 1.21 & {$[0.43-2.03]$} & 2.73 & {$[1.98-3.47]$} \\
\hline$\rho^{g}$ & 0.71 & {$[0.60-0.83]$} & 0.91 & {$[0.87-0.96]$} \\
$\rho^{z}$ & 0.76 & {$[0.67-0.87]$} & 0.68 & {$[0.55-0.80]$} \\
$\sigma^{\epsilon_{g}}$ & 0.29 & {$[0.18-0.40]$} & 0.16 & {$[0.11-0.22]$} \\
$\sigma^{\epsilon z}$ & 0.72 & {$[0.57-0.87]$} & 0.83 & {$[0.67-0.98]$} \\
$\sigma^{\epsilon_{r}}$ & 0.34 & {$[0.28-0.40]$} & 0.15 & {$[0.12-0.18]$} \\
$\rho^{g z}$ & 0.05 & {$[(-0.11)-0.21]$} & 0.31 & {$[0.15-0.45]$} \\
\hline \multicolumn{2}{l}{ Notes: The slope of the IS-curve is calculated by using the formula described } \\
in equation (2.1) and the posterior mean of the estimated structural parameters.
\end{tabular}

era (notice that the 90 percent intervals for the two estimates do not overlap at all) ${ }^{31}$. Since we can assume that the data updated our priors into the "right" direction, the estimated results are in favor of the hypothesis that the share of non-asset holders, interpreted as a proxy for the degree of U.S. financial regulation, decreased in the 1980s. This change drives the change in the sign of the slope of the IS curve ${ }^{32}$, since the estimates of the posterior mean of the inverse of labor supply elasticity of asset holders $\varphi$ are virtually unchanged: 2.98 in the pre-Volcker era and 2.86 in the Volcker-Greenspan period. Also, the estimated confidence interval entails in both cases the corresponding estimated posterior mean of the other period. Moreover, the estimates for the posterior mean of the degree of habit formation - another parameter that enters the slope of the IS curve - are also very close ( 0.43 and 0.36 , respectively).

Our results also confirm the results of inter alia CGG and LS by finding an inflation response below 1 in the interest rate rule in the pre-Volcker period. The estimated 90 percent interval goes from 0.42 to 0.62 . The range for the response coefficient in the Volcker-Greenspan era reaches from 1.90 to 3.36. It should be emphasized, however, that while our results do indicate that the observational implications of monetary policymaking, as described by the Taylor rule, have changed, this does not necessarily imply that policymaking has changed at a deeper level. Indeed, in light of our theoretical results, the estimates indicate that monetary policy has been

${ }^{31}$ Although the estimated share of liquidity constrained consumers for the pre-Volcker period are in line with the results by Campbell and Mankiw (1989), there are, however, differences in the interpretation of the results as discussed in Bilbiie and Straub (2005).

${ }^{32}$ The change in the sign of the IS clope was found independently by Bilbiie and Straub (2006) using single-equation, reduced-form GMM estimation. 
conducted with a view to minimize macroeconomic variability throughout the whole sample, since this strategy requires precisely a passive policy rule in the pre-Volcker period; in this sense, our results imply that there was no fundamental change in monetary policy, and are hence consistent with the findings of Sims and Zha (2006).

There are, however, several other factors worth discussing in further detail. The coefficient determining the degree of interest rate smoothing in the monetary policy rule differs significantly across the two periods. While the pre-Volcker era estimate indicates that there was almost no interest rate smoothing in the 1970s, the Federal Reserve had the tendency to adjust interest rates only gradually in response to changes in economic conditions in the Volcker-Greenspan era. If we believe that one important benefit of interest rate smoothing is to guide agents expectations about future interest rate developments, then the observed discrepancies can also be rationalized by the different degree of asset market participation in the two periods. A common argument (see, e.g., Woodford, 2003) is that the Fed can achieve its stabilization goals only insofar as its actions affect long-term interest rates. Hence, under rational expectations and full asset market participation, an effective response by the Fed requires that the private sector be able to believe that an increase in the short-term policy rate does also change the entire future path of interest rates. Obviously, this effect is more pronounced in an environment with high degree of asset market participation. As a result, it is not surprising that the degree of interest rate smoothing was significantly lower in the pre-Volcker era, where asset market participation was limited. The estimates of the degree of price-indexation do also differ significantly in the two periods: price-indexation was much more pronounced in the pre-Volcker period, which is in line with the stylized fact that inflation was highly persistent during this time.

Our results indicate that the two samples are also characterized by very different stochastic environments, which is consistent with the findings of a series of papers using different estimation techniques, such as Sargent, Williams, and Zha (2006) or Sims and Zha (2006), to quote the most recent examples. The persistence of the "demand" shocks is higher in the Volcker-Greenspan period, while the opposite is true for supply shocks. The correlation between supply and demand shocks is small in the pre-Volcker sample, but relatively large in the Volcker-Greenspan period, while the standard deviations of demand and monetary policy shocks have been falling. The standard deviation of "pure" cost push shocks $\sigma^{e_{z}}$ can be calculated from the standard deviation of the estimated, reduced-form supply shocks $\sigma^{\epsilon_{z}}$ using the standard formula for Choleski decomposition $\sigma^{e_{z}}=\sigma^{\epsilon_{z}} \sqrt{1-\left(\rho^{g z}\right)^{2}}$. This delivers 0.72 for the pre-Volcker and 0.78 for the Volcker-Greenspan periods respectively, suggesting that the standard deviation of cost-push shocks has been roughly stable.

All in all, our results indicate that there were changes in the U.S. economy in both structure and the distribution of shocks. Moreover, we identify some changes that were not identified before, most notably the change in asset market participation. Importantly, our results indicate that the structural changes were multidimensional, such that equilibrium determinacy was a feature of both the pre-Volcker and the Volcker-Greenspan samples. The crucial factors driving this result are the highly limited asset market participation combined with the passive monetary 
policy rule in the pre-Volcker sample. Otherwise put, if either policy were active or asset market participation were more widespread, equilibrium would have been indeterminate. As a result, the popular explanation (see, e.g., CGG, 2000 and LS, 2004) that sunspot shocks were the main source of macroeconomic volatility in the pre-Volcker era is not conducive with our hypothesis. ${ }^{33}$

Naturally, our framework implies that explanations for the Great Inflation, its conquest, and the difference in macroeconomic outcomes more generally, should be looked for elsewhere: either in the different distributions of fundamental shocks, or in the different economic structures in the two periods. In the former vein, many authors have argued (see for example Sargent, 2002) and papers quoted therein) that the two sub-samples were characterized by different stochastic environments (see also Cogley and Sargent, 2002). More specifically, Blinder (1982) argues that "the seventies were indeed special", regarding the relative size of supply shocks (see also Stock and Watson, 2003). The latter interpretation suggests that changes in the structure of the economy are crucial in driving the change in outcomes. Our paper contributes to this "structure vs. shocks" debate by investigating the relative role of each of these hypotheses in the following section.

\section{A Change in Structure of Economy or in Distribution of Shocks?}

In columns 1 and 3 of Table 3, we first present the stylized facts pertaining to U.S. output, inflation, and interest rate dynamics for the two chosen sub-samples. ${ }^{34}$ The results confirm the conventional wisdom that inflation was higher and more persistent and both inflation and output were much more volatile in the pre-Volcker era. In the next step, we analyze whether our model is able to reproduce some of these stylized facts. Therefore, in columns 2 and 4 of Table 3, we report the results of stochastic simulations using the estimated posterior mean of the moments of the shocks and the estimated posterior mean of the structural parameters for the pre-Volcker and Volcker-Greenspan periods, respectively. The results show, consistently with the data, that inflation was higher on average, more volatile and much more persistent in the earlier, "Great Inflation" period. The model also delivers the fall in the volatility of output that came to be known as the "Great Moderation", as well as the fall in the volatility in the interest rates.

In order to assess the relative importance of changes in the structure of the economy (as described by the deep parameters) versus those in the stochastic environment (captured by parameters pertaining to shock processes), we conduct two counterfactual simulations, reported in columns 5 and 6 of Table 3. Column 5, dubbed the "structure scenario," shows the outcomes that would have occurred if the stochastic environment were the pre-Volcker one, but the structure

${ }^{33}$ As the same authors show, sunspot shocks drive up both inflation and output, which is contrary to the stagflation observed in the pre-Volcker sample. Fundamental shocks, on the other hand, cannot be studied in an indeterminate equilibrium: they can have virtually any effects. CGG (2000) argue that even variability as explained by cost-push shocks is increased in a 'near-determinate' equilibrium, whereby the coefficient on inflation is slightly above one. But this merely explains why in a determinate equilibrium with an active rule responding less to inflation results in higher variability of the latter; dynamics in the indeterminate equilibrium are not pinned down.

${ }^{34}$ Notice that we present the moments of the HP-filtered output. 
Table 3. Stochastic Simulations

\begin{tabular}{lcccccc}
\hline & \multicolumn{2}{c}{ Pre-Volcker } & \multicolumn{2}{c}{ Volcker-Greenspan } & \multicolumn{2}{c}{ Scenario } \\
\hline & $\begin{array}{c}\text { Data } \\
(1)\end{array}$ & $\begin{array}{c}\text { Model } \\
(2)\end{array}$ & $\begin{array}{c}\text { Data } \\
(3)\end{array}$ & $\begin{array}{c}\text { Model } \\
(4)\end{array}$ & $\begin{array}{c}\text { "Structure" } \\
(5)\end{array}$ & $\begin{array}{c}\text { "Shocks" } \\
(6)\end{array}$ \\
\hline Means & & & & & & \\
\hline Output & 0.01 & 0.00 & 0.01 & 0.00 & 0.00 & 0.00 \\
Inflation & 6.28 & 4.46 & 3.17 & 3.25 & 3.25 & 4.40 \\
Interest Rate & 6.56 & 5.71 & 6.21 & 5.98 & 5.99 & 5.67 \\
& & & & & & \\
Standard Deviations & & & & & & \\
\hline Output & 1.26 & 1.25 & 0.97 & 0.98 & 1.51 & 1.01 \\
Inflation & 3.09 & 4.66 & 1.54 & 2.27 & 3.21 & 5.96 \\
Interest Rate & 2.21 & 2.56 & 2.10 & 2.03 & 1.63 & 2.09 \\
& & & & & & \\
Persistence, AR(1) & & & & & & 0.73 \\
\hline Output & 0.75 & 0.72 & 0.78 & 0.80 & 0.50 & 0.94 \\
Inflation & 0.89 & 0.88 & 0.46 & 0.52 & 0.75 & 0.88 \\
Interest Rate & 0.91 & 0.55 & 0.98 & 0.91 & & \\
& & & & & & \\
\hline
\end{tabular}

Notes: The "structure scenario" in column (5) presents the outcomes that would have occurred if the stochastic environment were the pre-Volcker one, but the structure of the economy were as in the Volcker-Greenspan sample. Column (6), which we call the "shocks scenario," shows the moments that would have occurred if the structure of the economy were the pre-Volcker one, but the economy were subject to the same shocks as in the Volcker-Greenspan period.

of the economy were as in the Volcker-Greenspan sample. Column 6, which we call the "shocks scenario," shows the moments that would have occurred if the structure of the economy (the deep parameters) were at their pre-Volcker values, but the economy were subject to the same shocks as in the Volcker-Greenspan period. The scenario that turns out to be closest to the actual Volcker-Greenspan outcomes would then indicate that the respective change (in shocks or structure, respectively) was relatively more important in explaining the change in outcomes. The results indicate that the "structure scenario" does better than the "shocks scenario", as it delivers the fall in the mean and persistence of inflation, the increase in average interest rates, and for both, inflation and interest rates the fall in volatility. For all these moments the "shocks" scenario predicts movements in the opposite direction. However, the "shocks scenario" is crucial in explaining the "Great Moderation" (the fall in output volatility) and, to a lesser extent, the increase in interest rate persistence. ${ }^{35}$ To summarize, both the structural change and the altering distribution of the shocks are important, albeit to different degrees, in order to explain the features of the Great Inflation and the change in macroeconomic dynamics in the Volcker-Greenspan era.

\section{A. Asset Market Participation, Monetary Policy, and Propagation of Shocks}

Our final experiments document the differences in the propagation of cost-push and

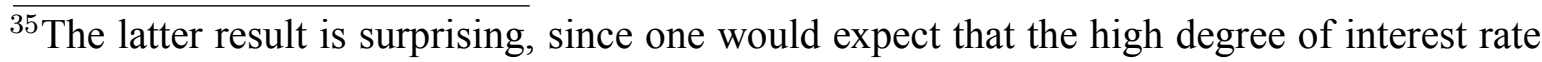
smoothing in the Volcker-Greenspan sample would be enough to make the "structure scenario" far better in this respect. 
"demand" shocks across the two samples, and the potential explanatory role of the changes in asset market participation and monetary policy. Figure 2 plots the impulse responses of output, inflation, and the nominal and real interest rate to a unit cost-push shock under three different scenarios. ${ }^{36}$ The pre-Volcker and the Volcker-Greenspan scenarios use the estimated posterior mean of the parameters to calculate the dynamic behavior of the model economy. The responses of the model confirm both the conventional wisdom and what we view as a good test for a theory purported to explain dynamics in that period: higher -and more persistent- inflation, low real rates, and negative comovement of inflation and the output. Moreover, responses of output and inflation have the same sign under both scenarios, but in the pre-Volcker scenario the response of inflation is larger and the response of output more negative. Notice also that in the pre-Volcker period, the real interest rate is persistently negative since the policy rule is passive.

The counterfactual scenario for the pre-Volcker period in Figure 2 evaluates the significance of a change in both asset market participation and monetary policy rule for the transmission of shocks. In particular, the impulse response functions of the counterfactual scenario describe the dynamics that would have occurred in the pre-Volcker period in response to a cost-push shock, if the Fed had followed the active policy rule adopted later in the Volcker-Greenspan period, and asset market participation had been of equal degree as estimated for the Volcker-Greenspan era. Interestingly, the responses are very similar to those of the Volcker-Greenspan era, indicating that the joint changes in these two parameters explain the bulk of the change in the transmission of cost-push shocks. A similar picture emerges from the impulse response functions following an identified ${ }^{37}$ "demand" shock presented in Figure 3.

\section{Conclusions}

The U.S. economy in the 1965-80 period was characterized by a high degree of financial regulation and limited asset-market participation; this changed in the early 1980 s, owing to both deregulation and financial innovation. We reviewed institutional evidence supporting this statement and outlined a dynamic general equilibrium model incorporating limited participation in asset markets. The model predicts a change in the sign of slope of the IS curve following an exogenous structural change in asset-market participation from low to high. We showed that under such conditions (labeled "non-Keynesian"), a passive policy rule is required by (i) equilibrium determinacy, and (ii) optimal policy in the sense of maximizing welfare. Furthermore, we argued that a central bank behaving in a welfare-maximizing manner would have switched from a passive to an active policy rule endogenously in response to a change in asset-market participation. We

\footnotetext{
${ }^{36}$ Arthur Burns emphasized the cost-push nature of inflation in the 1970s time and again in various speeches and statements as documented, for example, in Hetzel (1999) and Mayer (1999). Alan Blinder (1982) gives a careful account of the nature of the shocks and their impact on inflation. Both Ireland (2004) and LS (2004) argue that cost-push shocks have been the main cause of fluctuations in the pre-Volcker era, based on variance decompositions from a "new synthesis" model estimated by maximum likelihood and Bayesian methods, respectively.

${ }^{37}$ That is, an $e^{g}$ shock, taking into account that it also has an impact on the Phillips curve due to the triangular decomposition of the shock processes' VAR.
} 
provided empirical evidence, using Bayesian estimation techniques, that the data are compatible with our hypothesis that the sensitivity of aggregate demand to real interest rates changed sign from positive during the pre-Volcker period to negative thereafter. This sign change is triggered by the increase in asset market-participation in the Volcker-Greenspan period. Based on the foregoing theoretical and empirical results, we suggested that pre-Volcker Fed policy was better than is usually thought. Indeed, at a deep level, our results indicate that there was no change in monetary policy conduct; that is, policy was consistent throughout the whole sample with equilibrium determinacy and minimizing macroeconomic variability.

Since our framework implies that the equilibrium in the pre-Volcker period was determinate, we were able to study the effects of fundamental shocks. Stochastic simulations indicate that our model is able to replicate stylized facts of the U.S. economy for the period under scrutiny. Counterfactual simulations suggest that most, but not all, of the changes in outcomes can be explained by changes in the structure of the economy. However, the changes in shocks' distributions are important in order to explain some key changes, such as the fall in the volatility of output. Finally, we found that theoretical responses to fundamental shocks also conform with the stylized facts. Notably, we found that cost-push shocks generated considerably higher inflation, more persistent inflation, and deeper recessions in the pre-Volcker period than they have in the Volcker-Greenspan period. Most of the change in the transmission of shocks across the two samples can be accounted for by the changes in asset-market participation and in the monetary policy rule. All in all, our results contribute to an explanation of the change in business cycles based on a change in the structure of the economy combined with a change in the distributions of fundamental shocks, rather than on "better policy" that ruled out the previously prevailing effects of sunspot shocks.

The explanation proposed here abstracts from a few aspects emphasized by others: inflation bias; and information imperfections, beliefs, and learning. This is not to say that we believe such aspects have nothing to contribute to explaining the "Great Inflation". We merely argue that our explanation captures some features that other theories, by themselves, do not. In that sense, it could be part of the explanation, together with other, complementary and consistent theories. What weighting it should receive in solving the puzzle is, of course, an open issue. 


\section{GeNeRAL MOdeL}

In this Appendix, we outline the extended model used for estimation. We only spell out in detail the modification induced by the introduction of habit formation in consumption. ${ }^{38}$ The utility function is given by: $U_{j}\left(C_{j, t}, N_{j, t}\right)=\ln \left(C_{j, t}-\gamma C_{t-1}\right)-\nu N_{j, t}^{1+\varphi} /(1+\varphi)$. We impose preference homogeneity, such that agents" functional form of preferences is invariant to shifts in $\lambda$. Optimality conditions for consumers are:

$$
\begin{aligned}
R_{t}^{-1} & =\beta E_{t}\left[\frac{C_{S, t}-\gamma C_{t-1}}{C_{S, t+1}-\gamma C_{t}} \frac{P_{t}}{P_{t+1}}\right] \\
\nu N_{S, t}^{\varphi} & =\frac{1}{C_{S, t}-\gamma C_{t-1}} \frac{W_{t}}{P_{t}} \\
\nu N_{H, t}^{\varphi} & =\frac{1}{C_{H, t}-\gamma C_{t-1}} \frac{W_{t}}{P_{t}} .
\end{aligned}
$$

The budget constraint for non-asset holders is $C_{H, t}=\left(W_{t} / P_{t}\right) N_{H, t}$, while the budget constraint for asset holders-which has been used to obtain the Euler equation is ignored here and replaced -exploiting Walras' law- with the goods market equilibrium condition, or economy resource constraint. Since the firms" problem is completely standard, we refer the reader to Bilbiie (2003) for a detailed outline, in the case of no price indexation. The only modification with respect to that framework is that we introduce price indexation, in a by now conventional way. We refer the reader to Woodford (2003, Section 3.3.2) for a complete description of a model with price indexation. The "Phillips curve" of our model is listed in loglinearized form in Table 4, and the only other equation used from the firms" side is the linearized production function (also listed in the table). Finally, to obtain equilibrium we use all market clearing conditions.

We ensure that hours and consumption shares in steady state are equalized across groups by assumptions on technology leading to zero asset income (zero profits). The steady state is characterized by $R=\beta^{-1}$ where $R \equiv 1+r$ and by the aggregate production function $Y=N-F$, where $F$ is a fixed cost paid by all firms. ${ }^{39}$ Defining the steady-state net mark-up as $\mu \equiv(\varepsilon-1)^{-1}$, where $\varepsilon$ is the elasticity of substitution between intermediate goods, the share of real wage in total output can easily be shown to be $W N / P Y=\left(1+F_{Y}\right) /(1+\mu)$, where $F_{Y}=F / Y$ is the share of the fixed cost in steady-state output. Profits" share in total output is: $D_{Y}=D / Y=\left(\mu-F_{Y}\right) /(1+\mu)$. We assume that hours are the same for the two groups in steady state, $N_{H}=N_{S}=N$. Then, using the budget constraint for each group, consumption shares in total output are:

$$
\frac{C_{S}}{Y}=\frac{1+F_{Y}}{1+\mu}+\frac{1}{1-\lambda} \frac{\mu-F_{Y}}{1+\mu} ; \quad \frac{C_{H}}{Y}=\frac{1+F_{Y}}{1+\mu}
$$

${ }^{38}$ Our framework is slightly different from LS, since in their set up habit persistence in consumption is multiplicative. More importantly, they have inelastic labor supply, so lagged output does not enter the Phillips curve since habits have no effect on the intratemporal optimality condition.

${ }^{39}$ Note that this holds because price dispersion in steady state is 1 . 
Table 4. General Model Summary

\begin{tabular}{ll}
\hline Euler equation, $\mathrm{S}$ & $c_{S, t}-\gamma c_{t-1}=E_{t} c_{S, t+1}-\gamma c_{t}-(1-\gamma)\left(r_{t}-E_{t} \pi_{t+1}\right)$ \\
Labor supply, $\mathrm{S}$ & $\varphi n_{S, t}=w_{t}-\frac{1}{1-\gamma}\left(c_{S, t}-\gamma c_{t-1}\right)$ \\
Labor supply, $\mathrm{H}$ & $\varphi n_{H, t}=w_{t}-\frac{1}{1-\gamma}\left(c_{H, t}-\gamma c_{t-1}\right)$ \\
Budget constraint, $\mathrm{H}$ & $c_{H, t}=w_{t}+n_{H, t}$ \\
Production function & $y_{t}=(1+\mu) n_{t}$ \\
Phillips curve & $\pi_{t}=\frac{\beta}{1+\beta \omega} E_{t} \pi_{t+1}+\frac{\omega}{1+\beta \omega} \pi_{t-1}+\psi w_{t}, \psi \equiv(1-\theta)(1-\theta \beta) / \theta$ \\
Labor market clearing & $n_{t}=\lambda n_{H, t}+(1-\lambda) n_{S, t}$ \\
Goods market clearing & $y_{t}=c_{t}$ \\
Aggregate cons. & $c_{t}=\lambda c_{H, t}+(1-\lambda) c_{S, t}$. \\
Monetary policy & $r_{t}=\phi_{r} r_{t-1}+\left(1-\phi_{r}\right)\left(\phi_{\pi} E_{t} \pi_{t+1}+\phi_{y} y_{t}\right)+\varepsilon_{t}$. \\
\hline \multicolumn{2}{l}{ Note: We replaced the $\mathrm{S}$ budget constraint with the goods-market-clearing condition }
\end{tabular}

Since preferences are homogenous, steady-state consumption shares are also equal across groups, since intratemporal optimality conditions evaluated at steady state imply:

$$
C_{H}=C_{S}=\frac{1}{\nu N^{\varphi}} \frac{W}{P}+\gamma C .
$$

This instead requires either restrictions on technology making the share of asset income zero in steady state. For example, if the share of the fixed cost is equal to net markup $\mu=F_{Y}$ the share of profits in steady-state $D_{Y}$ is zero, consistent with evidence and arguments in Rotemberg and Woodford (1995), and with the very idea that the number of firms is fixed in the long run. Consumption shares are then:

$$
\frac{C_{H}}{Y}=\frac{C_{S}}{Y}=C_{Y}=1 .
$$

Using this in the previous equation be obtain steady-state hours as: $N=[\nu(1-\gamma)]^{-(1+\varphi)^{-1}}$.

We have used the steady-state ratios calculated above to obtain the loglinearized equilibrium conditions summarized in Table 4. Using the equations in the Table, and eliminating all variables other than output, inflation, and interest rate, we derive the IS and Phillips curves used in the estimation exercise and outlined in text. 
Figure 2. Impulse Response Functions Following a Cost-Push Shock
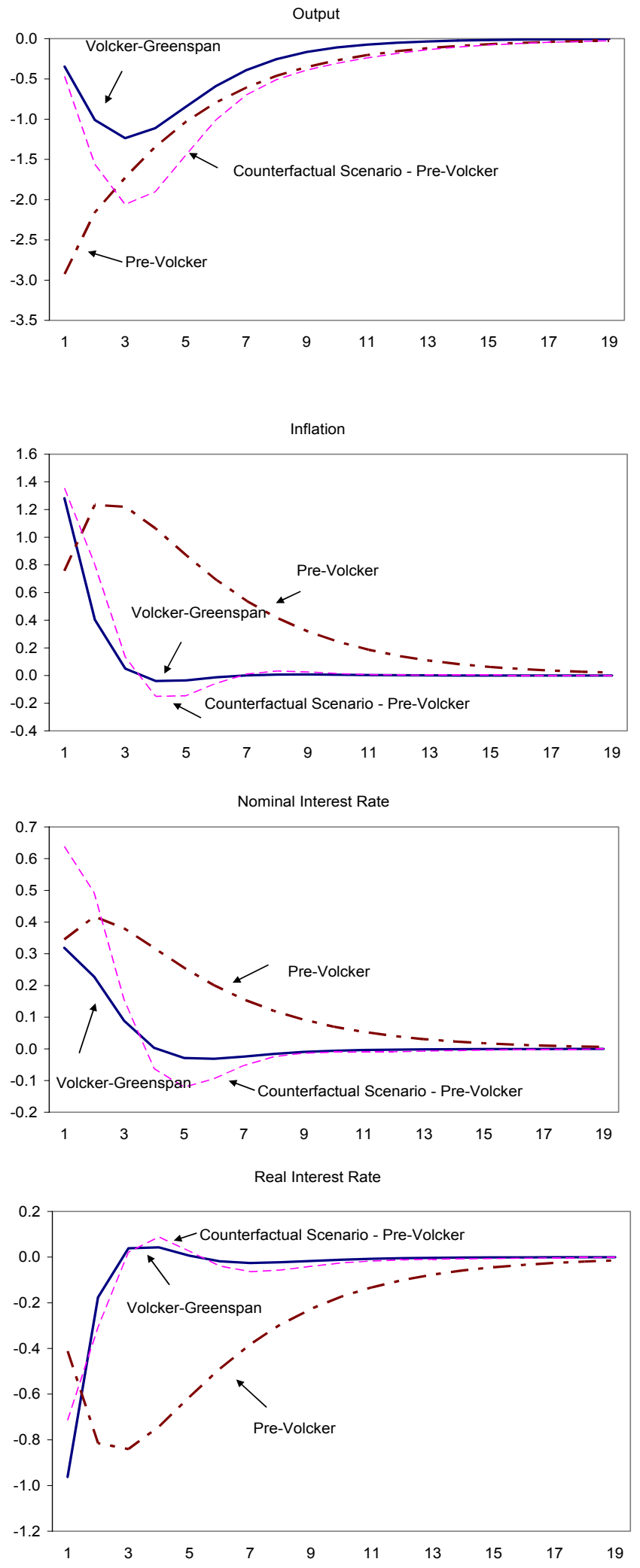
Figure 3. Impulse Response Functions Following an Aggregate Demand Shock
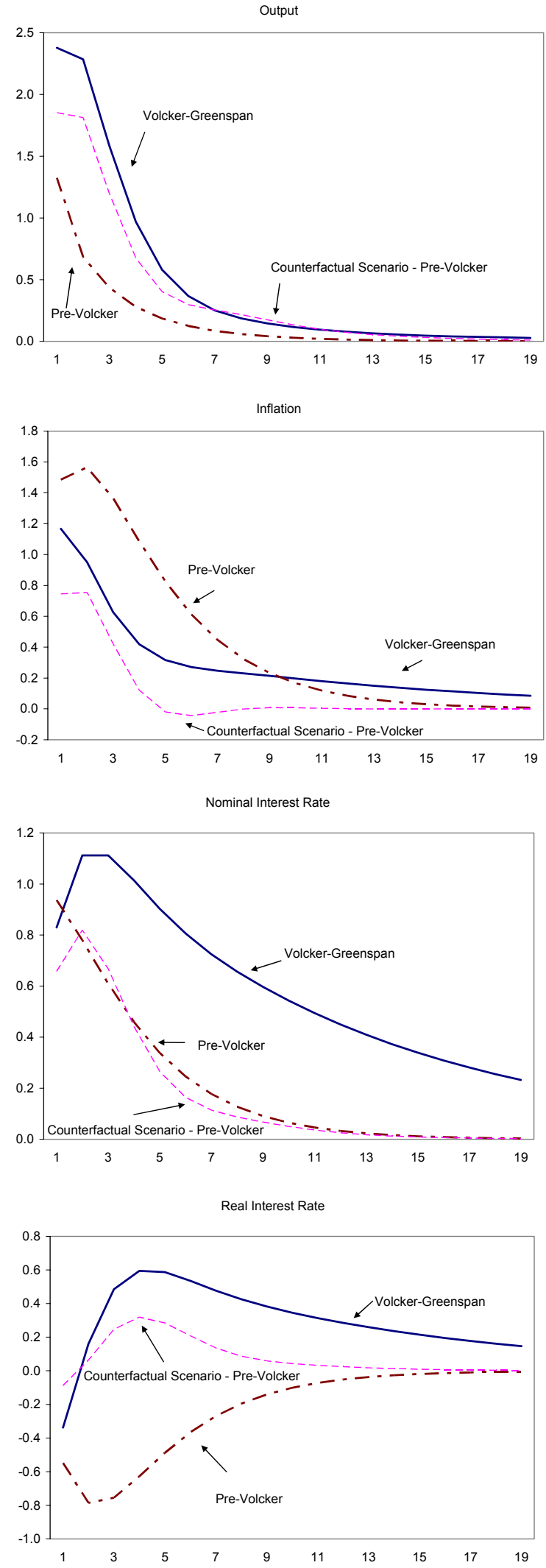


\section{References}

Alvarez F., R. Lucas Jr., and W. Weber, 2001, "Interest Rates and Inflation," American Economic Review, Vol. 91, No. 2, pp. 219-25.

Bilbiie, F.O., 2003, "Limited Asset Markets Participation, Monetary Policy and (Inverted) Keynesian Logic" (unpublished, Nuffield College, University of Oxford).

, and R. Straub, 2005, "Saving the Output Euler Equation" (unpublished, Nuffield College, University of Oxford and International Monetary Fund, Washington).

Blinder, A. S., 1982, "The Anatomy of Double Digit Inflation in the 1970's," in Inflation: Causes and Effects, ed. by Robert E. Hall, 261-82 (Chicago: University of Chicago Press).

Calvo, G., 1983, "Staggered Prices in a Utility-Maximizing Framework," Journal of Monetary Economics, Vol. 12, pp. 383-98.

Campbell, J. Y. and G. Mankiw, 1989, "Consumption, Income, and Interest Rates: Reinterpreting the Time Series Evidence," in NBER Macro Annual pp. 185-216 (Cambridge, Massachusetts: National Bureau of Economic Research).

Chari, V., L. Christiano, and M. Eichenbaum, 1999, "Expectation Traps and Discretion," Journal of Economic Theory, Vol. 81, No. 2, pp. 462-92.

Christiano, L., and C. Gust, 1999, "The Great Inflation of the 1970s" (unpublished, Chicago Northwestern University).

Clarida, R., J. Galí, and M. Gertler, 1999, "The Science of Monetary Policy: a New Keynesian Perspective," Journal of Economic Literature, Vol. 37, pp. 1661-707.

_ 2000, "Monetary Policy Rules and Macroeconomic Stability: Evidence and Some Theory," Quarterly Journal of Economics, Vol. 115, pp. 147-80

Cogley, T., and T. Sargent, 2002, "Drifts and Volatilities: Monetary Policies and Outcomes in the Post WWII U.S.," Review of Economic Dynamic, Vol. 8, No. 2, pp. 262-302.

Collard, F., and H. Dellas, H. 2004, "The Great Inflation of the 1970s," International Finance Discussion Papers, No. 799, Boards of Governor of the Federal Reserve System, Washington.

DeLong, B., 1997, "America's Only Peacetime Inflation: the '70s" ed. by C. Romer and 
D. Romer in "Reducing Inflation: Motivation and Strategy," (Chicago: University of Chicago Press).

Domeij, D., and M. Floden, 2004, "The labor supply elasticity and borrowing constraints: Why estimates are biased," forthcoming in the Review of Economic Dynamics.

Duca, J., 2001, "The Democratization of America's Capital markets," Economic and Financial Review, Vol. April 2001, Federal Reserve Bank of Dallas, Dallas.

Galí, J., D. Lopez-Salido., and J. Valles, 2003a, "Technology Shocks and Monetary Policy: Assessing the Fed's Performance," Journal of Monetary Economics, Vol. 50, pp. 72343.

— 2003b, "Rule-of-Thumb Consumers and the Design of Interest Rate Rules," Journal of Money, Credit and Banking, forthcoming.

Hetzel, R., 1999, "Arthur Burns and Inflation," Economic Quarterly, Vol. 1999, No.II, Federal Reserve Bank of Richmond, Richmond.

Ireland, P., 2004, "Technology Shocks in the New Keynesian model," forthcoming in the Review of Economics and Statistics.

Jones, C., 2002, "A Century of Stock Market Liquidity and Trading Costs," unpublished, Columbia Business School, New York.

Keynes, J.M., 1935, "The General Theory of Employment, Interest and Money," (Cambridge: MacMillan).

Lansing, K., 2000, "Exploring the Causes of the Great Inflation," Economic Letter, Federal Reserve Bank of San Francisco, San Francisco.

Lubik, T., and F. Schorfheide , 2003, "Computing Sunspot Equilibria in Linear Rational Expectations Models" Journal of Economic Dynamics and Control, Vol. 28(2), pp. 273-85.

— 2004, "Testing for Indeterminacy: An Application to U.S. Monetary Policy" American Economic Review, Vol.. 94(1), 190-217.

Mankiw, G., 2000, "The Savers-Spenders Theory of Fiscal Policy," American Economic Review, Vol. 90 (2), pp. 120-125.

Mayer, T., 1999, "Monetary Policy and the Great Inflation in the United States: The Federal Reserve and the Failure of Macroeconomic Policy, 1965-79," Edward Elgar Publishing. 
Meulendyke, A., 1989, "U.S. Monetary Policy and Financial Markets", Federal Reserve Bank of New York, New York.

Mishkin, F. S., 1991, "Financial Innovation and Current Trends in U.S. Financial Markets," NBER Working Paper Series, No. 3323 (Cambridge, Massachusetts: National Bureau of Economic Research).

New York Stock Exchange, 1986, "Shareownership 1985", unpublished, New York.

Orphanides, A., 2002, "Monetary Policy Rules and the Great Inflation," American Economic Review, Papers and Proceedings, Vol. 92, No. 2, pp.115-120.

Sargent, T., 1999, "The Conquest of American Inflation,"Princeton, (New Jersey: Princeton University Press).

— 2002, "Reactions to the 'Berkeley Story'," mimeo, Hoover Institution, Stanford.

—, N. Williams, and T. Zha, 2006, "Shocks and Government Beliefs: The Rise and Fall of American Inflation", American Economic Review, forthcoming.

Sims, C., and T. Zha, 2006, "Were there regime switches in U.S. monetary policy?", American Economic Review, forthcoming.

Silber, W., 1983, "The Process of Financial Innovation," American Economic Review, Vol. 73, No. 2, pp. 89-95

Stock, J., and M. Watson, 2002, "Has the Business Cycle Changed and Why?" NBER Macroeconomics Annual, (Cambridge, Massachusetts: National Bureau of Economic Research).

Taylor, J. B., 1993, "Discretion versus Policy Rules in Practice," Carnegie-Rochester Conference Series on Public Policy, Vol. 39, pp. 195-214.

__ 1999, "A Historical Analysis of Monetary Policy Rules," edited by Taylor, John: "Monetary Policy Rules", (Chicago: University of Chicago Press).

Vissing-Jorgensen, A., 2002, "Limited Asset Market Participation and the Elasticity of Intertemporal Substitution," Journal of Political Economy, Vol. 110, No. 4, pp. 825853.

Wenninger, J., 1984, "Financial Innovation in the United States," pp. 232-258 in 'Financial Innovations and Monetary Policy", Bank of International Settlements.

Wolff, E., 2000, "Recent Trends in Wealth Ownership," a paper for the Conference on 
Benefits and Mechanisms for Spreading Asset Ownership in the United States, New York University, December 10-12, 1998

, and A. Caner 2002, "Asset Poverty in the United States, 1984-1999: Evidence from the Panel Study of Income Dynamics," Working Paper No. 356 (Blithewood, New York: The Levy Institute).

Woodford, M., 2001, "The Taylor Rule and Optimal Monetary Policy," American Economic Review, Vol. 91, No. 2, pp. 232-37.

, 2003, "Interest and Prices: Foundations of a Theory of Monetary Policy," Princeton, (Princeton, New Jersey: Princeton University Press). 